\title{
ARTICLE OPEN \\ In vitro dissolution behavior of hydrogenated amorphous silicon thin-film transistors
}

\author{
Yuan Tian ${ }^{1}$, Andrew J. Flewitt ${ }^{2}$, Leigh T. Canham ${ }^{3}$ and Jeffery L. Coffer (iD)
}

Recent developments in biodegradable nanostructured crystalline silicon and flexible silicon-based electronic devices raise the significant question of the stability of standard amorphous silicon transistor platforms in biologically relevant environments. In this work, we evaluate the biodegradation of hydrogenated amorphous silicon thin film transistors. Specifically, using a combination of gravimetric analysis, optical imaging, and X-ray fluorescence, we investigate the fundamental stability of a simple hydrogenated amorphous silicon thin film transistor structure immersed in phosphate-buffered saline at physiological temperature $\left(37^{\circ} \mathrm{C}\right)$. In addition to the possible galvanic influence of associated metal electrodes in the degradation of such devices, implications for future device platforms are also discussed.

npj Materials Degradation (2018)2:41; https://doi.org/10.1038/s41529-018-0063-0

\section{INTRODUCTION}

Flexible electronics has become a mature field with a developing range of applications. ${ }^{1}$ A number of recent reports have also outlined exciting approaches regarding the properties of watersoluble nanoscale crystalline Si circuits that may be conveniently used in biological applications, as they can physically disappear at a controlled time, i.e., resorb in the body as therapeutic devices or sensors. $^{2-5}$ The possible utility of these devices has been directed to a range of anatomical targets, ${ }^{6-8}$ most commonly to dermalrelated applications ${ }^{9,10}$ but also extends to challenging locations such as the brain. ${ }^{11,12}$

The above studies have rendered the crystalline silicon component of circuitry biodegradable via nanostructuring. However, hydrogenated amorphous silicon (a-Si:H) has recently been shown to have much higher solubility than crystalline silicon (c-Si) in biological media. ${ }^{13}$ This raises, of course, the intriguing possibility that standard a-Si:H structures, as commonly employed in fabricated devices, ${ }^{14}$ could be optimized to be biodegrade without nanostructuring, which is often an expensive process. This would have the further advantages of device uniformity over large areas that amorphous thin films offer. The dissolution of c-Si or a$\mathrm{Si}: \mathrm{H}$ into biological media results in the formation of silicic acid, which has been identified as non-toxic. ${ }^{13,15,16}$ However, the metalbased contacts and additional associated structures are influenced by this Si dissolution, and are expected to demonstrate a different physiological response. Therefore, it is critical to further understand the possible dissolution behavior of a-Si:H, in particular, the dissolution rate and the parameters that influence such dissolution. Using a combination of optical imaging and X-ray fluorescence (XRF), here we address these fundamental questions for a simple thin film transistor (TFT) structure immersed in physiologically relevant phosphate-buffered saline (PBS).

\section{RESULTS}

a-Si:H TFT structure

The TFTs used in these experiments were fabricated via a bottom gate method; the so-called inverted staggered structure. A single, common chromium metal gate was used to address all devices simultaneously. Onto this was deposited an amorphous silicon nitride gate dielectric, an intrinsic a-Si:H channel semiconductor, a phosphorous-doped $\mathrm{n}^{+}$a-Si:H source and drain contact layer, and finally a bilayer of chromium and aluminum to act as top source and drain contacts. The initial a-Si:H layer thickness is $\sim 300 \mathrm{~nm}$ with a $50 \mathrm{~nm} \mathrm{n}{ }^{+}$a-Si:H contact layer above. After etching, the exposed a-Si:H thickness is $\sim 200 \mathrm{~nm}$. Radio frequency $(13.56 \mathrm{MHz})$ plasma-enhanced chemical vapor deposition was used for the silicon-based layers and thermal evaporation for the metals. Reactive ion etching is used to pattern the a-Si:H layers. In the inverted staggered structure, the back side of the a-Si:H channel is exposed. Figure 1 is a schematic diagram of an array of a-Si: H TFTs patterned onto a Corning 7059 glass plate.

\section{Position-dependent dissolution}

All dissolution data of a-Si:H TFTs were collected in PBS (pH 7.4) at $37^{\circ} \mathrm{C}$ in order to gain information as to how the released Si or other elements from TFT devices may influence the environment or the human body. After soaking one a-Si:H TFT device $(8.3 \mathrm{~mm} \times$ $6.4 \mathrm{~mm}$ ) in $2 \mathrm{~mL}$ PBS for 137 days, a simple visible observation identified that there is a significant dissolution of the TFT film and such dissolution across the device is not uniform. To better understand this dissolution behavior, 11 different areas from TFTs were monitored via optical imaging as a function of time in subsequent PBS immersion experiments (Fig. 2a). The relative film coating status of each image was calculated by the Image-Pro Plus program. The calculated dissolution percentage is highly dependent on area of interest selection. There are two examples in Fig. $2 \mathrm{~b}$ illustrating a typical calculation of dissolution percentage of

\footnotetext{
${ }^{1}$ Department of Chemistry, Texas Christian University, Fort Worth, TX 76129, USA; ${ }^{2}$ Electrical Engineering Division, Cambridge University, Cambridge CB3 0FA, UK and ${ }^{3}$ Nanoscale Physics, Chemistry, and Engineering Research Laboratory, University of Birmingham, Birmingham B15 2TT, UK

Correspondence: Jeffery L. Coffer (j.coffer@tcu.edu)
}

Received: 12 September 2018 Accepted: 21 November 2018

Published online: 13 December 2018 
same area (area 10 in illustration Fig. 2a) after soaking in PBS buffer for 6 days as well as 70 days.

Figure $3 \mathrm{~b}$ presents optical images from different AOIs (shown in Fig. 3a) of one TFT device soaking in $2 \mathrm{~mL}$ PBS at $37^{\circ} \mathrm{C}$ for 137 days (Fig. 3b) and associated \% dissolution of different areas (Fig. 3a). Elemental crystalline Si lacks measurable solubility in aqueous media at room temperature or physiological temperature. In amorphous form, significant dissolution in buffered media at $37^{\circ} \mathrm{C}$ takes place, with $\sim 90 \%$ (by mass) occurring for a-Si microspheres within 10 days. $^{13}$ The observed dissolution presumably starts from these types of areas. For example, Area 3 and Area 10 are presumably silicon-rich because of their yellow color. After 137 days of soaking in PBS buffer, the dissolution percentage of each area is as high as $90 \%$. In contrast, for Area 11 after 137 days of soaking in PBS buffer, only $2.7 \%$ dissolution is observed.

\section{XRF analyses}

In order to probe possible composition dependence of the above degradation of the film structure, XRF mapping experiments ( $\mu$ XRF) were performed. Two useful types of information are possible, in principle. The first, as a control experiment, is to verify the anticipated location of the TFT components (with regard to composition) prior to immersion in PBS at physiological temperature. The second is to analyze relative changes in film composition at a given location in the TFT structure after extended immersion in PBS at $37^{\circ} \mathrm{C}$ (137 days).

Figure 4 is an $\mu$-XRF two-dimensional (2-D) map of an a-Si:H TFT structure before soaking into PBS buffer for 137 days. Based on a

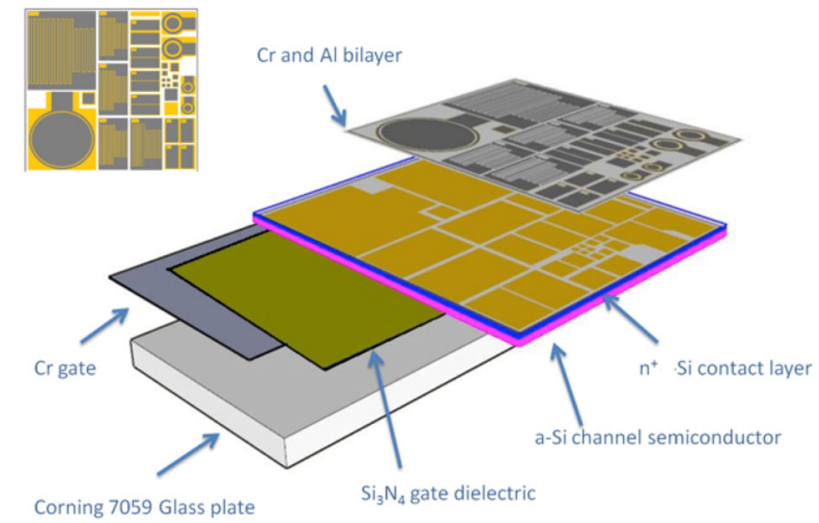

Fig. 1 Expanded schematic illustration of an a-Si:H TFT, with a top view in the upper left inset. The a-Si:H channel layer is also patterned into individual TFT islands (not shown)

a

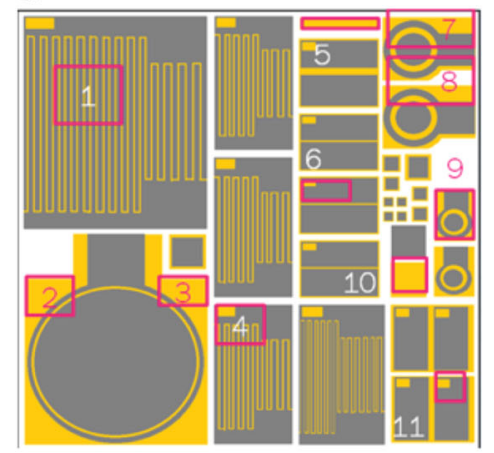

comparison with the optical images shown above in Fig. 3, it is clear that Areas 3 and 10 are silicon-rich, whereas Area 11 is $\mathrm{Cr}$ rich. Hence, the above distinct differences in spatially dependent dissolution behavior arise because of their composition at a particular location.

Figure 5 presents an image of the $\mu$-XRF 2-D map of an a-Si:H TFT structure after soaking into PBS buffer for 137 days, and Table 1 provides a comparison of mass percentages of $\mathrm{Si}, \mathrm{Cr}$, and $\mathrm{Al}$ of similar area (blue rectangular area in Figs. 4 and 5) in a-Si:H TFT before and after soaking in PBS for 137 days. Unfortunately, the rather large $\mathrm{Si}$ content in the underlying Corning glass substrate obscures any detection of appreciable changes in Si concentration as a consequence of PBS exposure at physiological temperature over the time period evaluated. The very slight increase in $\mathrm{Si}$ percentage likely arises because of: (1) condensation reactions of monomeric $\mathrm{Si}(\mathrm{OH})_{4}$ over time to form new silica layers; and/or (2) loss of metal ( $\mathrm{Cr}$ and $\mathrm{Al})$ over time, resulting in relatively enhanced Si levels. The latter conclusion is reinforced by the slight increase in $\mathrm{Ba}$ concentration (present in the Corning glass) over the 137 day immersion time. There are slight losses in both $\mathrm{Al}$ and $\mathrm{Cr}$ content over time in this type of structure upon soaking in PBS. It should also be noted that a strong signal of $P$ appears after 137 days, consistent with precipitation of a phosphate phase on the structure.

\section{Local concentration effects}

The dissolution of a-Si:H is also influenced by the local buffer concentration. The dissolution status comparison of different areas (originally defined in Fig. 2a) among two TFT structures (two pieces of $8.3 \times 6.4 \mathrm{~mm}$ dimension) in $1 \mathrm{ml}$ PBS for 84 days, one TFT structure in $1 \mathrm{ml}$ PBS for 87 days, and one TFT structure in $2 \mathrm{ml} \mathrm{PBS}$ for 80 days are presented in Fig. 6 . The dissolution status of one TFT in $2 \mathrm{ml}$ PBS is slightly faster than that of one TFT in $1 \mathrm{~mL}$ PBS, whereas being significantly faster than that of two TFT in $1 \mathrm{~mL}$ PBS. These results suggest that when two TFT devices are soaked in $1 \mathrm{~mL}$ PBS, the dissolution equilibrium involving silicic acid formation is inhibited. The dissolution is position-dependent, and mostly initiated at Si-rich areas.

\section{DISCUSSION}

Possible chemical reactions responsible for the dissolution of $\mathrm{Si}$ are as follows:

$\mathrm{Si}+2 \mathrm{H}_{2} \mathrm{O} \rightarrow \mathrm{SiO}_{2}+2 \mathrm{H}_{2}(\mathrm{~g})$

$\mathrm{SiO}_{2}+2 \mathrm{H}_{2} \mathrm{O} \rightarrow \mathrm{Si}(\mathrm{OH})_{4}$

The dissolution of $\mathrm{Si}$ involves hydrolysis to ultimately form $\mathrm{Si}$ $(\mathrm{OH})_{4},{ }^{13,16,17}$ with the formation of $\mathrm{SiO}_{2}$ involved as an

b

$\begin{array}{ll}\text { (i) Area 10, Day } 6 & \text { (ii) Area 10, Day } 70\end{array}$

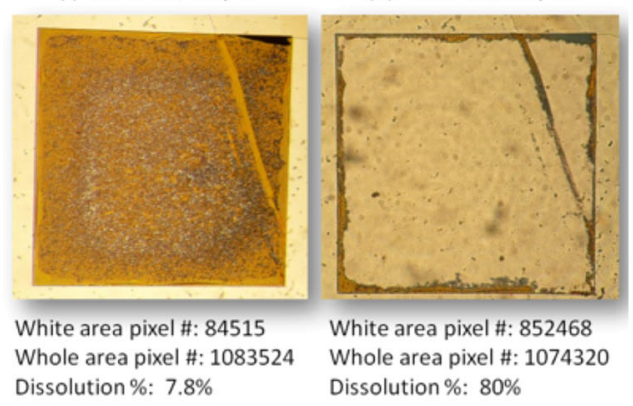

Fig. 2 a Illustration image of 11 AOls from an a-Si:H TFT device. b Typical calculations of dissolution percentages in Area 10 after (i) 6 days and (ii) 70 days soaking in PBS buffer 
a

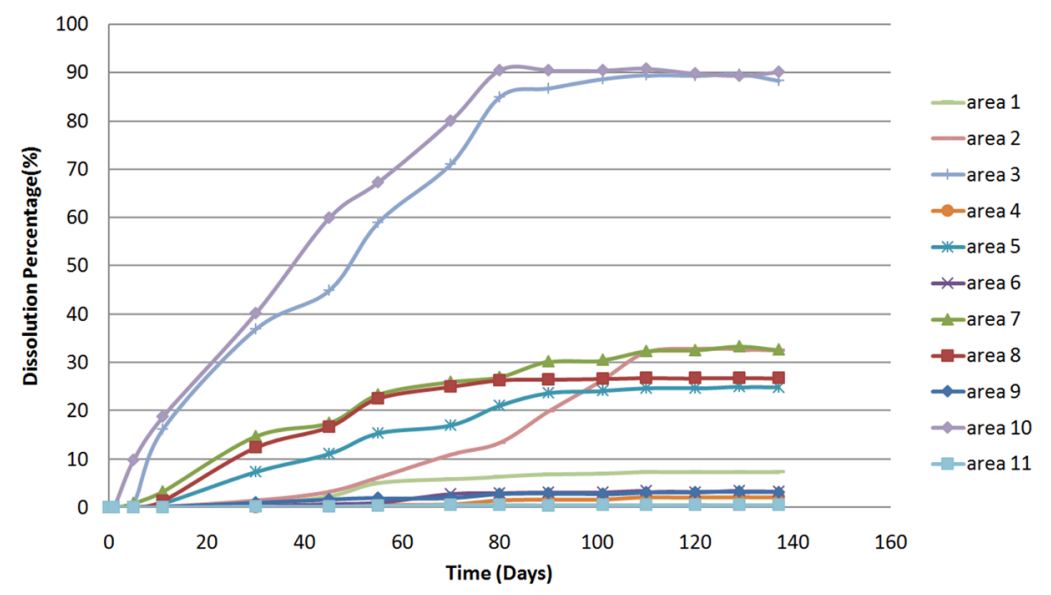

b

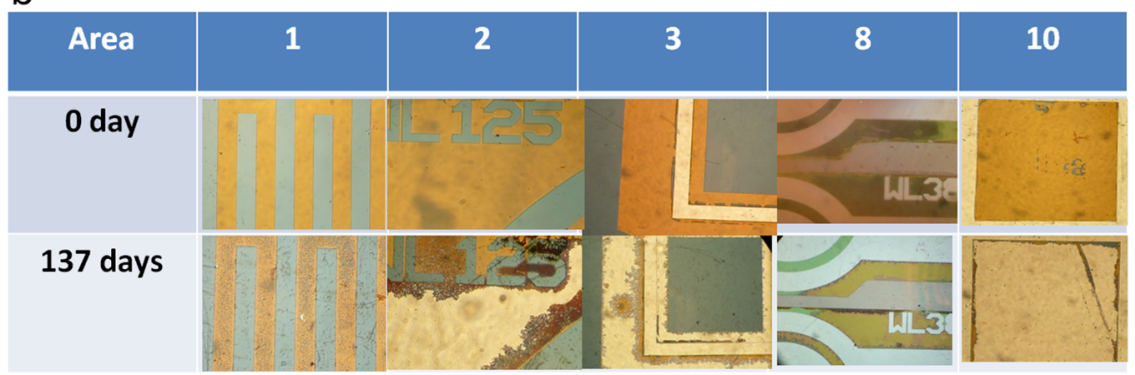

Fig. 3 Dissolution behavior of a single a-Si TFT device in $2 \mathrm{~mL}$ PBS. a The dissolution percentage of 11 different areas (Fig. $2 \mathrm{a}$ ) versus time of one TFT soaking in $2 \mathrm{ml}$ PBS for 137 days. b Optical images before and after 137 days PBS exposure for Areas 1, 2, 3, 8, 10

intermediate. ${ }^{18}$ The growth of $\mathrm{SiO}_{2}$ on a silicon surface is rather complicated. In 1990, Morita investigated the growth of native oxide on a silicon surface in ultrapure water. ${ }^{18}$ Results indicated that dissolved oxygen concentration is a critical factor that influences the formation of $\mathrm{SiO}_{2}$, with the growth of $\mathrm{SiO}_{2}$ suppressed in ultrapure water by decreasing the dissolved oxygen concentration. The Si dissolution rate is also likely influenced by $\mathrm{pH}$, as the hydroxide ion is a catalyst for the hydrolysis that is the origin of the dissolution process. As discussed above, a-Si:H is a non-crystalline allotropic form of silicon. Crystalline silicon consists of four-fold coordinated $\mathrm{Si}$ atoms that are tetrahedrally bonded to four neighboring silicon atoms, forming a well-ordered lattice with long-range order. In contrast, a-Si:H has no long-range order and the atoms form a continuous random network. In the dissolution process, oxygen species need to break $\mathrm{Si}-\mathrm{Si}$ bonds to produce $\mathrm{SiO}$ bonds. The energy needed to break $\mathrm{Si}-\mathrm{Si}$ bonds in amorphous $\mathrm{Si}$ is much lower than that in crystalline $\mathrm{Si}$ (associated with the population of bond energies in this random network, more amenable to attack), which is consistent with the dissolution of $\mathrm{Si}$ in a-Si:H TFT devices only in the amorphous Si layer. Based on a similar explanation, an increased temperature affects the average vibrational energy of the system, facilitating cleavage of $\mathrm{Si}-\mathrm{Si}$ bonds and their subsequent dissolution in an aqueous medium. Furthermore, although such moieties are hydrophobic, it is also possible that the presence of hydrogen $(\sim 10$ at $\%)$ can play a role in the dissolution as well.

The analysis of soluble silicon (in the form of $\mathrm{Si}(\mathrm{OH})_{4}$ ) is usually estimated by the colorimetric method of Dienert \& Wandenbulcke, ${ }^{19}$ which makes use of the yellow color $\left(\mathrm{H}_{8} \mathrm{Si}\left(\mathrm{MoO}_{7}\right)_{6} \mathrm{H}_{2} \mathrm{O}\right)$ that develops on the interaction of soluble silica and ammonium molybdate in acidic solution. The presence of high concentration of phosphate in PBS buffer strongly interferes with the result, owing to the formation of phosphomolybdate. The addition of sulfuric acid and oxalic acid can reduce this interference. ${ }^{20}$ Given the insensitivity of XRF to changes in local Si concentration for this system, the above modified molybdate assay was employed to provide a macroscopic evaluation of Si dissolution over time. As shown in Table 2, the daily dissolution rate of silicon in PBS of two TFT structures in $1 \mathrm{~mL}$ PBS is $0.015 \mu \mathrm{g} / \mathrm{mL} / \mathrm{d}$, one TFT in $1 \mathrm{~mL}$ PBS is $0.05 \mu \mathrm{g} / \mathrm{mL} / \mathrm{d}$ and two TFTs in $1 \mathrm{~mL}$ PBS is $0.08 \mu \mathrm{g} / \mathrm{mL} / \mathrm{d}$ before 100 days. After 100 days, only one TFT in $1 \mathrm{~mL}$ PBS is detectable, and the daily dissolution rate of silicon is $0.034 \mu \mathrm{g} / \mathrm{mL} / \mathrm{d}$.

According to the optical images of dissolution in different areas (Fig. 2), the dissolution of $\mathrm{Cr}$ only occurs when there is large area of $\mathrm{Si}$ dissolved because $\mathrm{Cr}$ metal is passivated by oxygen, forming a thin protective oxide surface layer. The existing $\mathrm{Si}$ layer presumably protects the $\mathrm{Cr}$ layer. The dissolution of $\mathrm{Cr}$ on an aSi:H TFT was also demonstrated by macroscopic XRF measurements of the entire TFT structure. According to XRF data, the $\mathrm{Cr}$ counts of two TFT devices soaking in $1 \mathrm{~mL}$ PBS drops $0.7 \%$ in 70 days in total; that of one TFT in $1 \mathrm{~mL}$ PBS drops $2.7 \%$ in 55 days; and that of one TFT in $2 \mathrm{~mL}$ PBS drops $3.4 \%$ in 57 days. Consistent with the silicon dissolution result, the faster the silicon dissolves in PBS, the more unprotected $\mathrm{Cr}$ is exposed, and the associated $\mathrm{Cr}$ dissolves more rapidly as well.

The dissolution data reported here establishes a baseline of practical data for the dissolution of standard a-Si:H TFT devices in simulated biological media. Such circuitry contains intrinsic and doped hydrogenated amorphous silicon, amorphous silicon nitride, aluminum, and chromium. All three silicon compounds have good biocompatibility and varying degrees of resorbability. ${ }^{21-25}$ The metals $\mathrm{Cr}$ and $\mathrm{Al}$, however, should be replaced with alternatives. ${ }^{26}$ The processes of dissolution may be adjustable in real time and/or sensitive to the properties of the surrounding chemical or biological environment, or changes in temperature, pressure, or light. Corresponding to the dissolution of $\mathrm{Si}$ or $\mathrm{Cr}$, the efficiency of TFT devices may be changed because of the critical role of the gate dielectric and semiconductor where the channel is 

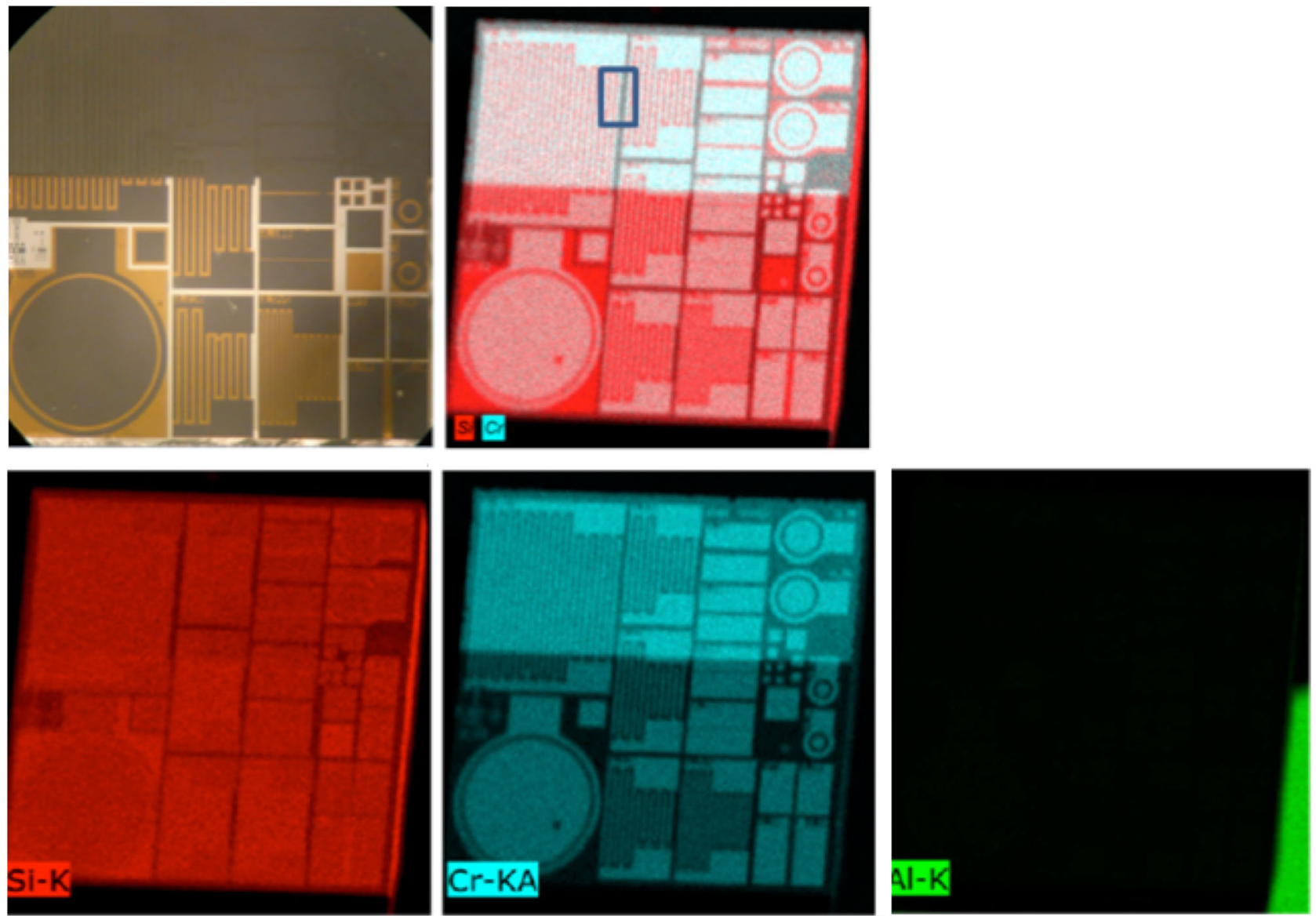

Fig. $4 \mu$-XRF 2-D maps of one a-Si:H TFT device before soaking into PBS buffer

formed at the interface. Most importantly, the anticipated cytotoxicity from the released $\mathrm{Cr}$ and $\mathrm{Al}$ may restrict the biomedical use of a-Si:H TFT devices as currently formulated. A logical next step, building upon the data and characterization methods herein, is to now fabricate similar circuitry with more biocompatible and biodegradable metal contacts and a fully biodegradable polymer substrate. ${ }^{27}$ Such combinations could markedly expand the opportunities of a-Si:H TFTs in biomedical applications, providing a much lower cost biodegradable circuitry platform than those achievable via nanostructuring.

\section{METHODS}

Fabrication of a-Si:H TFTs

The TFTs used in these experiments were fabricated via a bottom gate method (inverted staggered structure) on a Corning 7059 glass plate with a structure as described in Fig. 1 and described in the Results section. Typical dimensions of such a structure is $8.3 \mathrm{~mm} \times 6.4 \mathrm{~mm}$.

\section{Soluble silica assay}

The silica concentration in aqueous solution (in the form of monomeric $\mathrm{Si}$ $(\mathrm{OH})_{4}$ ) is usually estimated by the colorimetric method, so-called soluble silica assay or ammonium molybdate assay, which uses the yellow color of the silicomolybdic acid that is formed when ammonium molybdate and hydrochloric acid are added. ${ }^{28,29}$ When the concentration of soluble silica is high, it can be directly detected; whereas when the concentration of soluble silica is low, reducing agent need to be added to convert silicomolybdic acid to a dark blue or purple product. In the original protocol we used to detect silica concentration, five kinds of solutions were prepared: hydrochloric acid $(0.25 \mathrm{M})$, ammonium molybdate $(5 \% \mathrm{w} / \mathrm{v})$, disodium ethylenediaminetetraacetic acid (EDTA) $(1 \% \mathrm{w} / \mathrm{v})$, sodium sulfite $(17 \% \mathrm{w} / \mathrm{v})$, and silica standard solution $\left(0.05 \mathrm{mg} / \mathrm{mL} \mathrm{SiO}_{2}\right)$. All samples were analyzed in duplicate. After $0.5 \mathrm{~mL}$ of each sample was transferred into individual $50 \mathrm{~mL}$ Erlenmeyer flasks, $9.5 \mathrm{~mL}$ de-ionized (DI) water was added into each flask. After the addition of $5 \mathrm{~mL}$ hydrochloric acid $(0.25 \mathrm{M}), 5 \mathrm{~mL}$ ammonium molybdate $(5 \% \mathrm{w} / \mathrm{v})$ and $5 \mathrm{~mL}$ disodium EDTA $(1 \% \mathrm{w} / \mathrm{v})$ into each flask, it is necessary to swirl and wait for 5 min until all species thoroughly react. Then $10 \mathrm{~mL}$ sodium sulfite solution $(17 \% \mathrm{w} / \mathrm{v})$ was added and the flasks were allowed to stand $30 \mathrm{~min}$. A wavelength of $700 \mathrm{~nm}$ and a $1 \mathrm{~cm}$ cell was used to measure the absorbance of the samples.

However, because the body fluid we used to mimic biological environment is PBS (pH of 7.4), the relatively high concentration of phosphate in PBS results in a positive result for the blank samples $(0.5 \mathrm{~mL}$ of PBS buffer). This is unexpected, as this reduction of the silicomolybdate complex by sodium sulfite to molybdenum blue of composition $\mathrm{Mo}_{3} \mathrm{O}_{8} \cdot \mathrm{H}_{2} \mathrm{O}$ in low acidity should not be accompanied by color from phosphomolybdates. ${ }^{28,29}$ When the concentration of phosphate is higher than $1 \mathrm{ppm}$, the test result is not accurate and sensitive. ${ }^{28,29}$

Subsequent work by Armstrong concerning detection of silicate in sea water indicated that the addition of sulfuric acid will make the excess molybdate convert rapidly into a form that cannot be reduced to a blue compound, and the addition of oxalic acid (or citric or tartaric acid) after acidification with sulfuric acid will fully suppress the formation of molybdenum blue from phosphate and eliminate this interference. ${ }^{20}$ However, the addition of oxalic acid may sacrifice the sensitivity of this experiment. Owing to the low concentration of soluble silica of TFTs in PBS buffer, samples were tested in reduced amount of reagents to make sure the final concentration of silica is within the concentration limit $0.1-50 \mu \mathrm{g} /$ L.

In the revised soluble silica assays used in these experiments, six kinds of solutions were prepared: hydrochloric acid $(0.25 \mathrm{M})$, ammonium molybdate $(5 \% \mathrm{w} / \mathrm{v})$, sulfuric acid $(50 \% \mathrm{w} / \mathrm{v})$, oxalic acid $(1 \% \mathrm{w} / \mathrm{v})$, sodium sulfite $(17 \%$ $\mathrm{w} / \mathrm{v})$, and silica standard solution $\left(0.05 \mathrm{mg} / \mathrm{mL} \mathrm{SiO}_{2}\right)$. All samples were analyzed in duplicate. PBS served as a reagent blank. After $0.5 \mathrm{~mL}$ of each sample was transferred into individual $50 \mathrm{~mL}$ Erlenmeyer flasks, $4.5 \mathrm{~mL} \mathrm{DI}$ water was added into each flask. After the addition of $3 \mathrm{~mL}$ hydrochloric 

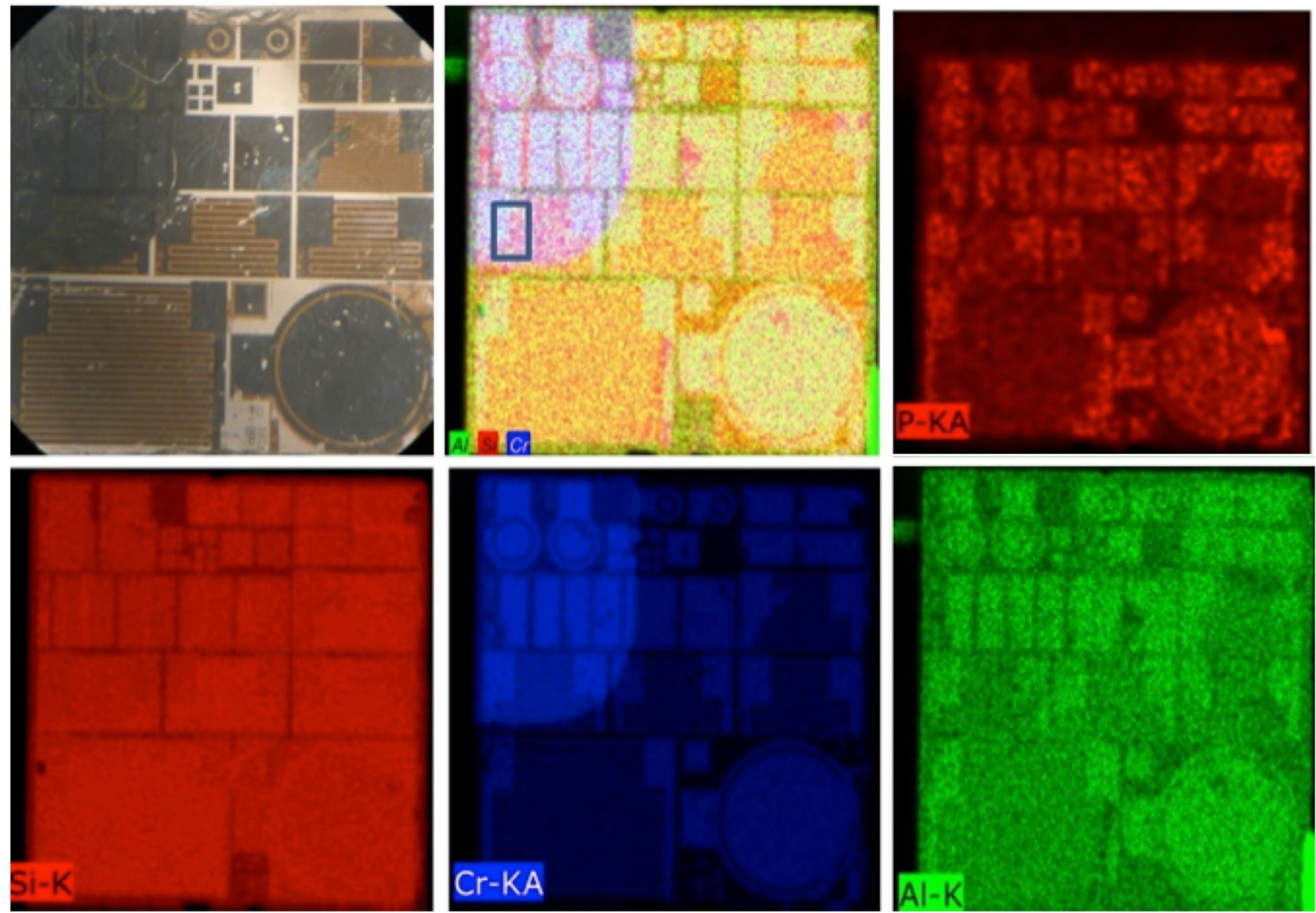

Fig. $5 \mu$-XRF 2-D maps of one a-Si:H TFT device after soaking in PBS buffer for 137 days at $37^{\circ} \mathrm{C}$

Table 1. Element mass percentage comparison of a-Si:H TFT before and after soaking in PBS buffer for 137 days

\begin{tabular}{lclll}
\hline & Al (\%) & Si (\%) & Cr (\%) & Ba (\%) \\
\hline 0 Days & 10.5 & 44.3 & 4.9 & 36.6 \\
137 Days & 8.7 & 45.9 & 4.2 & 37.4 \\
\hline
\end{tabular}

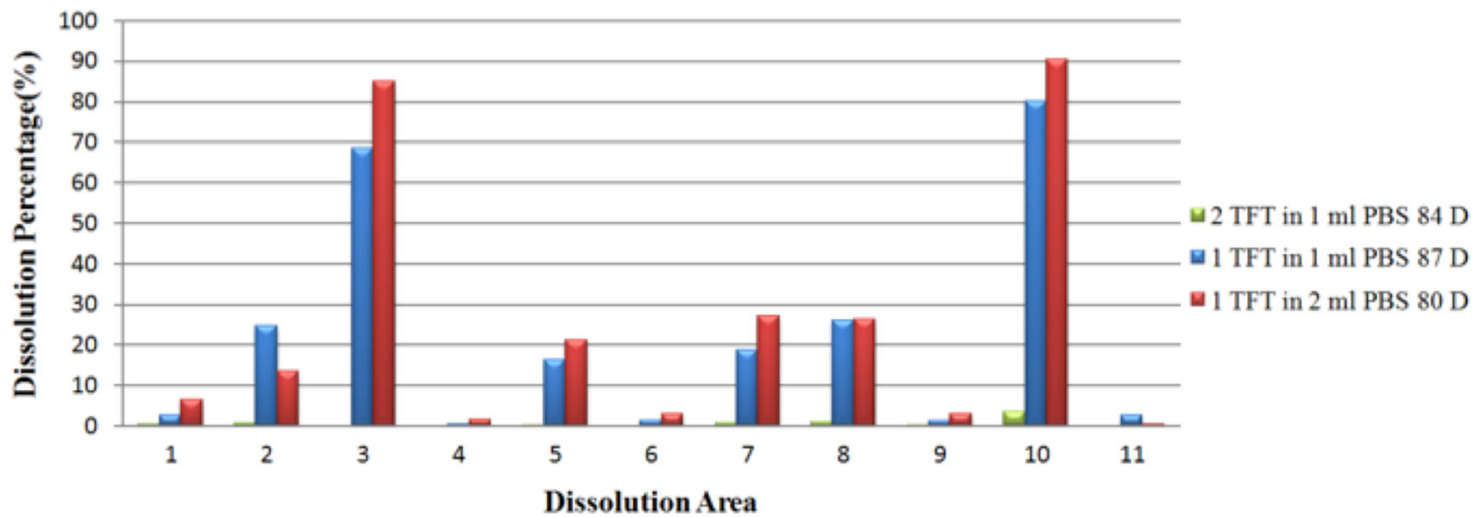

Fig. 6 Comparative dissolution behavior of a-Si:H TFT samples under different conditions: two TFT devices in $1 \mathrm{~mL}$ PBS (84 days), one TFT device in $1 \mathrm{~mL}$ PBS (87 days), and one TFT device in $2 \mathrm{~mL}$ PBS (80 days) 
acid and $1 \mathrm{~mL}$ ammonium molybdate into each flask, it is necessary to swirl and wait for $10 \mathrm{~min}$ until all species thoroughly react. Then $2 \mathrm{~mL}$ sulfuric acid and $1 \mathrm{~mL}$ oxalic acid were added into each flask. After another $10 \mathrm{~min}$, $4 \mathrm{~mL}$ sodium sulfite was added and the flasks were allowed to stand overnight to achieve a more stable color. A wavelength of $700 \mathrm{~nm}$ and a $1 \mathrm{~cm}$ cell was used to measure the absorbance of the samples. Silica concentration can be determined from a plot of the absorbencies of the standards against their known concentrations.

\section{Instrumentation}

Optical images were recorded under a Nikon Eclipse TS-100 inverted microscope by a Nikon CCD camera. Mass percentages of different elements presented in a-Si:H TFT devices were measured by a M4 Tornado $\mu$-XRF from Bruker Instruments. A Beckman DU-64 spectrophotometer was used for measuring absorbance for dissoluble silica assays. The dissolution of $\mathrm{Cr}$ and $\mathrm{Si}$ was also monitored by a Bruker Tracer-III SD XRF spectrometer from the TCU Department of Geology. The dissolution of selected areas of TFTs was also evaluated using time-dependent changes in optical images of samples immersed in PBS at $37^{\circ} \mathrm{C}$ for various periods of time. Image-Pro Plus software was used to measure the ratio between the number of pixels of a given color in selected areas of interest and the total pixel number of the selected area. Si-rich areas, for example, are associated with yellow colored regions of interest; aluminum, silver; chromium, blue.

\section{DATA AVAILABILITY}

The data that support the findings of this study are available from the data repository maintained by the Mary Couts Burnett Library of Texas Christian University at https:// doi.org/10.18776/DS/22103.

\section{ACKNOWLEDGEMENTS}

We thank Ted Juzwak of Bruker Nano for assistance with the XRF measurements. This work was supported by a grant from the Robert A. Welch Foundation (Grant P-1212 to JLC).

\section{AUTHOR CONTRIBUTIONS}

The experiments were designed by Y.T., L.T.C, and J.L.C. a-Si:H TFT samples were fabricated by A.J.F. All dissolution experiments were conducted by Y.T., with L.T.C, A.J. F., and J.L.C. assisting with analysis of data. All co-authors wrote and edited the manuscript.

\section{ADDITIONAL INFORMATION}

Competing interests: The authors declare no competing interests.

Publisher's note: Springer Nature remains neutral with regard to jurisdictional claims in published maps and institutional affiliations.

\section{REFERENCES}

1. Nathan, A. et al. Flexible electronics: the next ubiquitous platform. Proc. IEEE 100, 1486-1517 (2012).

2. Hwang, S. W. et al. A physically transient form of silicon electronics. Science 337, 1640-1644 (2012).

3. Lee, Y. K. et al. Dissolution of monocrystalline silicon nanomembranes and their use as encapsulation layers and electrical interfaces in water-soluble electronics. ACS Nano. 11, 12562-12572 (2017).

4. Chen, Y., Kim, Y. S., Tillman, B. W., Yeo, W. H. \& Chun, Y. Advances in materials for recent low-profile implantable bioelectronics. Mater. (Basel) 11, 522 (2018).

5. Kang, S.-K. et al. Dissolution chemistry and biocompatibility of silicon- and germanium-based semiconductors for transient electronics. ACS Appl. Mater. Inter. 7, 9297-9305 (2015).
6. Hwang, S.-W. et al. Biodegradable elastomers and silicon nanomembranes/ nanoribbons for stretchable, transient electronics, and biosensors. Nano Lett. 15, 2801-2808 (2015).

7. Kang, S.-K., Koo, J., Lee, Y. K. \& Rogers, J. A. Advanced materials and devices for bioresorbable electronics. Acc. Chem. Res. 51, 988-998 (2018).

8. Someya, M., Bao, Z. \& Malliaras, G. G. The rise of plastic electronics. Nature 540, 379-385 (2016).

9. Kim, D. H. et al. Epidermal electronics. Science 333, 838-843 (2011).

10. Wang, S., Oh, J. Y., Xu, J., Tran, H. \& Bao, Z. Skin-inspired electronics: an emerging paradigm. Acc. Chem. Res 51, 1033-1045 (2018).

11. Kang, S.-K. et al. Bioresorbable silicon electronic sensors for the brain. Nature $\mathbf{5 3 0}$, 71-76 (2016).

12. $\mathrm{Yu}, \mathrm{K}$. J. et al. Bioresorbable silicon electronics for transient spatiotemporal mapping of electrical activity from the cerebral cortex. Nat. Mater. 15, 782-791 (2016).

13. Shabir, Q. et al. Medically biodegradable hydrogenated amorphous silicon microspheres. Silicon 3, 173-176 (2011).

14. Flewitt A. J. Hydrogenated amorphous silicon thin film transistors (a-Si TFT's). In Handbook of Visual Display Technology. (Springer, Berlin, 2014).

15. Reffitt, D. M., Ogston, N., Jugdaohsingh, R., Cheung, H. F. \& Evans, B. A. Orthosilicic acid stimulates collagen type 1 synthesis and osteoblastic differentiation in human osteoblast-like cells in vitro. Bone 32, 127-135 (2003).

16. Anderson, S. H. C., Elliott, H., Wallis, D. J., Canham, L. T. \& Powell, J. J. Dissolution of different forms of partially porous silicon wafers under simulated physiological conditions. Phys. Stat. Sol. 197, 331-335 (2003).

17. Rimstidt, J. D. \& Barnes, H. L. The Kinetics of silica-water reactions. Geochim. Cosmochim. Acta 44, 1683-1699 (1980).

18. Morita, M., Ohmi, T., Hasegawa, E., Kawakami, M. \& Ohwada, M. Growth of native oxide on a silicon surface. J. Appl. Phys. 68, 1272-1281 (1990).

19. Diénert, F. \& Wandenbulcke, F. Sur le dosage de la silice dans les eaux. C. R. Acad. Sci., Paris. 176, 1478-1480 (1923).

20. Armstrong, F. A. J. The determination of silicate in sea water. J. Mar. Biol. Assoc. UK 30, 149-160 (1951)

21. Olofsson, J. et al. Evaluation of silicon nitride as a wear resistant and resorbable alternative for total hip joint replacement. Biomatter 2, 94-102 (2012).

22. Kotzar et al. Evaluation of MEMS materials of construction for implantable medical devices. Biomaterials 23, 2737-2750 (2002).

23. Xi., Y. et al. Corrosion resistance of biodegradable magnesium alloy coated with hydrogenated amorphous silicon. J. Biomed. Mater. Res. 89A, 717-726 (2009).

24. Liu, X. et al. Formation of apatite on hydrogenated amorphous silicon film deposited by PECVD. Mat. Chem. Phys. 101, 124-128 (2007).

25. Mussano, F. et al. Hydrogenated amorphous silicon coatings may modulate gingival cell response. Appl. Surf. Sci. 436, 603-612 (2018).

26. Katz, S. A. et al. The toxicology of chromium with respect to its chemical speciation: a review. J. Appl. Toxicol. 13, 217-224 (1993).

27. Canham, L. T. Nanosilicon for nanomedicine: a step towards biodegradable electronic implants? Nanomedicine 8, 1573-1576 (2013).

28. Bunting, W. E. Determination of soluble silica in very low concentrations. Ind. Eng. Chem. Anal. Ed. 16, 612-615 (1944).

29. Kahler, H. L. Determination of soluble silica in water: a photometric method. Ind. Eng. Chem. Anal. Ed. 13, 536-539 (1941).

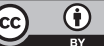

Open Access This article is licensed under a Creative Commons Attribution 4.0 International License, which permits use, sharing, adaptation, distribution and reproduction in any medium or format, as long as you give appropriate credit to the original author(s) and the source, provide a link to the Creative Commons license, and indicate if changes were made. The images or other third party material in this article are included in the article's Creative Commons license, unless indicated otherwise in a credit line to the material. If material is not included in the article's Creative Commons license and your intended use is not permitted by statutory regulation or exceeds the permitted use, you will need to obtain permission directly from the copyright holder. To view a copy of this license, visit http://creativecommons. org/licenses/by/4.0/.

(c) The Author(s) 2018 